\title{
Could NICE guidance on the choice of blood pressure lowering drugs be simplified?
}

Reecha Sofat and colleagues argue that prescribing advice needs updating in the light of recent evidence that all classes of blood pressure lowering drugs are broadly equivalent

\author{
Reecha Sofat specialist registrar in clinical pharmacology ${ }^{1}$, Juan P Casas senior lecturer in \\ epidemiology ${ }^{23}$, Anthony M Grosso honorary associate professor in clinical pharmacy ${ }^{14}$, Brian $\mathrm{N}$ \\ C Prichard emeritus professor of clinical pharmacology ${ }^{1}$, Liam Smeeth professor of clinical \\ epidemiology ${ }^{3}$, Raymond MacAllister professor of clinical pharmacology ${ }^{1}$, Aroon D Hingorani \\ professor of genetic epidemiology ${ }^{12}$
}

\footnotetext{
${ }^{1}$ Centre for Clinical Pharmacology, University College London, London WC1E 6JJ, UK; ${ }^{2}$ Faculty of Population Health Sciences, University College London; ${ }^{3}$ Faculty of Epidemiology and Population Health, London School of Hygiene and Tropical Medicine, London ; ${ }^{4}$ Department of Pharmacy, University College London Hospital NHS Foundation Trust and School of Pharmacy, University College London
}

High blood pressure is the most common modifiable cause of cardiovascular morbidity and mortality worldwide, ${ }^{1}$ and blood pressure lowering drugs from four major classes (angiotensin converting enzyme (ACE) inhibitors and angiotensin receptor blockers, $\beta$ blockers, calcium channel blockers, and diuretics) are prescribed in large volumes. Among these, treatment would be dictated by cost or tolerability if all drugs were of similar efficacy and safety and had an additive effect when used in combination. However, guidance from the National Institute for Health and Clinical Excellence (NICE) and the British Hypertension Society emphasises differences between drug classes and combinations in blood pressure response and clinical outcomes.

NICE's recommendations are based on the view that younger patients ( $\leq 55$ years) are more responsive to drugs targeting the renin-angiotensin system than older patients; that $\beta$ blockers are less effective than the other drug classes for the prevention of stroke; and that $\beta$ blockers and diuretics lead to a clinically important increase in the risk of type 2 diabetes. Consequently, its 2006 guidelines gave primacy to angiotensin modifying drugs and calcium channel blockers, with a substantial influence on prescribing behaviour in England and Wales (fig $1 \Downarrow$ ). ${ }^{2}$ The updated guidelines published last August (www.nice.org.uk/ CG127) maintain this view, but how strong is the evidence?

\section{Stratification by age}

Current NICE recommendations represent an evolution of the view that blood pressure is best lowered with $\beta$ blockers or ACE inhibitors in patients under 55 years (in whom an activated renin-angiotensin system may be an important mechanism) and diuretics or calcium channel blockers in older patients (because sodium retention, with suppression of the renin-angiotensin system, may be more important). This was based primarily on the findings of a study $(n=36)$ that rotated young patients through monthly treatment with each of four main classes of blood pressure lowering drugs and assessed the effect on blood pressure. $^{3}$

By 2006, NICE had relegated $\beta$ blockers to third or fourth line therapy because of concerns about reduced protection from stroke, ${ }^{2}$ and last year NICE dropped diuretics as a first line option. Renin declines with age, ${ }^{4}$ and the major drug classes do differ in their effect on the renin-angiotensin system. However, the performance of age as a proxy for stratifying blood pressure response or in comparison with measurement of renin concentrations (now possible with a rapid, cheap assay) has yet to be formally evaluated. Moreover, a meta-analysis including data from 11000 participants from 42 trials, which included people younger than 55, concluded that the "blood pressure reduction from combining drugs from these 4 classes can be predicted on the basis of additive effects."7 This conclusion even included combinations of two drugs that both suppress or activate renin.

\section{Efficacy of $\boldsymbol{\beta}$ blockers}

Two sources of evidence were influential in NICE's relegation of $\beta$ blockers from first line treatment: the Anglo Scandinavian Cardiovascular Outcomes Trial (ASCOT), published in 2005, ${ }^{8}$ 
and three meta-analyses examining the efficacy of $\beta$ blockers in the prevention of cardiovascular events, published in 2005-6. ${ }^{9-11}$

ASCOT was a randomised trial comparing an amlodipine based treatment regimen (with addition of perindopril and then doxazosin if required) with an atenolol based treatment regimen (with the addition of bendroflumethazide and then doxazosin if required) to achieve a blood pressure $<140 / 90 \mathrm{~mm} \mathrm{Hg}$. The trial was terminated early on the advice of the data safety monitoring committee because of a significant treatment difference in favour of patients randomised to the amlodipine based regimen for two secondary end points (stroke and total cardiovascular events). There was no difference in the primary end point of non-fatal myocardial infarction or fatal coronary heart disease. Blood pressure was lower in the group randomised to amlodipine rather than atenolol by around $2.7 / 1.9 \mathrm{~mm} \mathrm{Hg}$. The trialists' analysis suggested the blood pressure difference was insufficient to explain the disparity in event rates, but an accompanying commentary reached the opposite conclusion.

A subsequent meta-analysis examined trials comparing $\beta$ blockers with other blood pressure lowering drugs. ${ }^{9}$ Stroke risk was $16 \%$ higher ( $95 \%$ confidence interval $4 \%$ to $30 \%$ ) among patients randomised to $\beta$ blockers than among those taking other drugs. Two other meta-analyses reached similar conclusions. ${ }^{10} 11$ However, the inclusion and exclusion criteria of these meta-analyses were not uniform. A re-analysis shows that the pooled estimate of the comparative efficacy of $\beta$ blockers for preventing stroke is sensitive to which trials were considered eligible (see supplementary analysis on bmj.com). Furthermore, they did not account for blood pressure differences between the treatment arms. The achieved blood pressure favoured the comparator drug over $\beta$ blockers in all scenarios, which may bias the outcome in favour of the comparator drug. The blood pressure disparity is unlikely to be because $\beta$ blockers are inherently less effective at lowering blood pressure than other drugs ${ }^{14}$ but rather because achieving a precisely equivalent blood pressure reduction in two arms of a comparator trial is extremely challenging. Nevertheless this is essential for a fair comparison of the efficacy of two drug classes.

Two new comprehensive meta-analyses now supersede these studies. ${ }^{15} 16$ These examined the efficacy of all major blood pressure drug classes (not just $\beta$ blockers) in the context of the achieved reductions in blood pressure. The Blood Pressure Treatment Trialists Collaboration, which incorporated information from 190606 participants across 31 treatment trials, concluded that all classes of drug were broadly equivalent with respect to protection from serious cardiovascular events. ${ }^{15}$ The analysis indicated a log-linear association between blood pressure reduction and the relative risk of events, in keeping with predictions from observational studies. A second analysis by Law and colleagues, which included information from 147 published trials among 464000 participants, concluded the protective effect of lowering blood pressure on coronary heart disease was the same for all drug classes with two exceptions. ${ }^{16}$

Calcium channel blockers had a small class specific advantage in protecting from stroke over all other classes. The authors considered that this probably accounted for most of the apparent disadvantage of $\beta$ blockers in stroke protection because calcium channel blockers had been the most common comparator drug in trials of $\beta$ blockers.

Law and colleagues also found $\beta$ blockers to have a specific action over and above their blood pressure lowering effects in preventing a recurrence in the first few years after a coronary heart disease event. Because blood pressure is an important risk factor for recurrent events in patients with established cardiovascular disease, as well as those at risk of a first event, it had seemed counterintuitive that $\beta$ blockers should be an unfavoured treatment before a patient has had a coronary event but a preferred option immediately afterwards. In the longer term, their benefits were consistent with the degree of blood pressure lowering and proportionally similar to that seen in individuals with no prior event. ${ }^{16}$

\section{Risk of type 2 diabetes}

Patients receiving $\beta$ blockers or thiazides rather than other drugs such as ACE inhibitors are at higher risk of diabetes. ${ }^{18}$ But what is the magnitude of the blood glucose increase; by how much is the risk of diabetes increased; and, importantly, how does this affect the risk of cardiovascular events?

In the ASCOT trial, diabetes risk was increased among people randomised to the atenolol-bendroflumethiazide arm (hazard ratio for the comparison of groups randomised to amlodipine rather than atenolol was $0.70,95 \%$ confidence interval 0.63 to 0.78 ), yet the average absolute difference in blood glucose concentration was only $0.2 \mathrm{mmol} / \mathrm{L}$ (SD $2.08 \mathrm{mmol} / \mathrm{L}$, $\mathrm{P}<0.0001){ }^{8}$ The seemingly substantial increase in the risk of diabetes arises because an average increase in glucose of as little as $0.2 \mathrm{mmol} / \mathrm{L}$ leads to a substantial increase in the proportion of people marginally exceeding the diagnostic fasting blood glucose threshold of $7 \mathrm{mmol} / \mathrm{L}$ and therefore being classified as diabetic (fig 3 on bmj.com).

However, the evidence is not compelling that this small average increase in glucose translates into a shortfall in protection from stroke or coronary heart disease. In the Asia Pacific Cohort Studies Collaboration (a participant level meta-analysis of 237 468 people), a decrease in fasting glucose by $1 \mathrm{mmol} / \mathrm{L}$ was associated with a $21 \%(18 \%$ to $24 \%)$ lower incidence of stroke and a $23 \%$ (19\% to $27 \%)$ lower incidence of ischaemic heart disease. ${ }^{18}$ If the association is causal, and assuming a log-linear relation between glucose and risk of cardiovascular events, an increase in fasting glucose of $0.2 \mathrm{mmol} / \mathrm{L}$ should confer about a $5 \%$ increase in the risk of stroke, which is less than the differences reported in the recent trials. Moreover, recent overviews of prospective observational studies indicate that although the risk of coronary heart disease is linearly and modestly increased above a fasting glucose value of $5 \mathrm{mmol} / \mathrm{L}$, the risk of stroke is substantially raised only at fasting glucose values well above $7 \mathrm{mmol} / \mathrm{L}$ (fig 4 in supplementary analysis on bmj.com). ${ }^{19-21}$

Furthermore in the ALLHAT trial (in which 33357 patients were randomised to chlortalidone, amlodipine, or lisinopril) there was a difference in blood glucose of $0.16 \mathrm{mmol} / \mathrm{L}$ in the amlodipinegroup compared with the chlortalidone group, with an odds ratio for diabetes of 0.73 (0.58 to 0.91$)$. Yet the hazard ratio for stroke was 0.93 (0.82 to 1.06). There was only a small blood pressure disparity between the chlortalidone arm and amlodipine arms (blood pressure difference amlodipine versus chlortalidone $0.8 \mathrm{~mm} \mathrm{Hg}$ systolic $(\mathrm{P}=0.03) /-0.8 \mathrm{~mm} \mathrm{Hg}$ diastolic $(\mathrm{P}<0.001))$. This suggests that the observed differences in risk of stroke in these trials are more likely to be explained by differences between the treatment arms in blood pressure rather than glucose. The relevance of the small average increase in glucose is further questioned by recent trials that indicate that tight glucose control does not necessarily lead to a reduction in cardiovascular event rates.

Despite this, NICE cost effectiveness models were based on the assumption that $\beta$ blockers provide less protection from stroke than all other drug classes (not just calcium channel blockers) 
and that any diagnosis of diabetes is associated with twice the risk of mortality and other cardiovascular disease events compared with no diabetes. It is not clear whether the known effects of $\beta$ blockers in preventing recurrent coronary heart disease events were modelled in the economic analysis.

\section{How does guidance compare internationally?}

Guidance in the United States published before 2006 recommends diuretics as first line treatment, with $\beta$ blockers given equal standing to the other drug classes. ${ }^{24}$ The European Society of Hypertension and the European Society of Cardiology guideline from 2007 also recommends $\beta$ blockers and thiazide diuretics as first line options in the absence of contraindications, except among those with established metabolic syndrome or a particularly high risk of diabetes. ${ }^{25}$ However guidance in Scotland and New Zealand has changed in line with NICE's 2006 recommendations.

\section{Resolving uncertainty}

Network (mixed treatment) meta-analysis was used to evaluate the comparative efficacy and safety of the main blood pressure lowering drug classes in relation to cardiovascular events ${ }^{28}$ and diabetes, ${ }^{17}$ but these analyses preceded the recent large influential trials and meta-analyses. An updated network meta-analysis that includes efficacy and safety outcomes and which accounts for blood pressure and glucose differences between treatment arms could help reduce any remaining uncertainty.

In the meantime, the most recent evidence indicates that the four classes of drug are more similar than different in their clinical efficacy and safety and that their effects in combination are additive, irrespective of mechanism. The initial choice of drug class and combination could thus rest on price, tolerability, and specific contraindications in individual patients. This simplification would benefit healthcare commissioners, doctors, and patients.

Contributors and sources: RS, JPC, AG, LS, RJM, and ADH are engaged in research on the primary and secondary prevention of cardiovascular disease. RS holds a NIHR clinical lectureship in translational medicine. $\mathrm{RS}$ is an honorary specialist registrar and RJM and ADH are honorary consultants at University College London Hospital cardiovascular risk clinic. All authors have contributed to the conception, design, analysis, and interpretation of the data, as well as drafting and critical and final review of the manuscript.

Competing interests: All authors have completed the ICJME unified disclosure form at www.icmje.org/coi_disclosure.pdf (available on request from the corresponding author) and declare no support from any organisation for the submitted work; LS is supported by a Wellcome Trust Senior Fellowship, ADH has received honorariums for speaking at courses and meetings on cardiovascular disease prevention, which were donated in part to charity, has provided non-remunerated advice to GlaxoSmithKline and London Genetics, and is a member of the JBS3 guidelines development group. RS, RJM and ADH are members of the British Hypertension Society.

Provenance and peer review: Not commissioned; externally peer reviewed.
1 Lawes CM, Vander Hoorn S, Law MR, Elliott P, MacMahon S, Rodgers A. Blood pressure and the global burden of disease 2000. Part II: estimates of attributable burden. $J$ Hypertens 2006;24:423-30.

2 NICE, British Hypertension Society. NICE clinical guideline 34. Hypertension: management of hypertension in adults in primary care. 2006. www.nice.org.uk/CG34.

3 Dickerson JE, Hingorani AD, Ashby MJ, Palmer CR, Brown MJ. Optimisation of antihypertensive treatment by crossover rotation of four major classes. Lancet 1999:353:2008-13.

4 Belmin J, Levy BI, Michel JB. Changes in the renin-angiotensin-aldosterone axis in later life. Drugs Aging 1994;5:391-400.

5 Seifarth C, Trenkel S, Schobel H, Hahn EG, Hensen J. Influence of antihypertensive medication on aldosterone and renin concentration in the differential diagnosis of essential hypertension and primary aldosteronism. Clin Endocrinol 2002;57:457-65.

6 De Bruin RA, Bouhuizen A, Diederich S, Perschel FH, Boomsma F, Deinum J. Validation of a new automated renin assay. Clin Chem 2004;50:2111-6.

7 Wald DS, Law M, Morris JK, Bestwick JP, Wald NJ. Combination therapy versus monotherapy in reducing blood pressure: meta-analysis on 11000 participants from 42 trials. Am J Med 2009;122:290-300

8 Dahlof B, Sever PS, Poulter NR, Wedel H, Beevers DG, Caulfield M, et al. Prevention of cardiovascular events with an antihypertensive regimen of amlodipine adding perindopril as required versus atenolol adding bendroflumethiazide as required, in the Anglo-Scandinavian Cardiac Outcomes Trial-blood pressure lowering arm (ASCOT-BPLA): a multicentre randomised controlled trial. Lancet 2005;366:895-906.

9 Lindholm LH, Carlberg B, Samuelsson O. Should beta blockers remain first choice in the treatment of primary hypertension? A meta-analysis. Lancet 2005;366:1545-53.

10 Bradley HA, Wiysonge CS, Volmink JA, Mayosi BM, Opie LH. How strong is the evidence for use of beta-blockers as first-line therapy for hypertension? Systematic review and meta-analysis. J Hypertens 2006;24:2131-41.

11 Khan N, McAlister FA. Re-examining the efficacy of beta-blockers for the treatment of hypertension: a meta-analysis. CMAJ 2006;174:1737-42.

12 Poulter NR, Wedel H, Dahlof B, Sever PS, Beevers DG, Caulfield M, et al. Role of blood pressure and other variables in the differential cardiovascular event rates noted in the Anglo-Scandinavian Cardiac Outcomes Trial-blood pressure lowering arm (ASCOT-BPLA). Lancet 2005;366:907-13.

13 Staessen JA, Birkenhager WH. Evidence that new antihypertensives are superior to older drugs. Lancet 2005;366:869-71.

14 Law MR, Wald NJ, Morris JK, Jordan RE. Value of low dose combination treatment with blood pressure lowering drugs: analysis of 354 randomised trials. BMJ 2003;326:1427.

15 Turnbull F, Neal B, Ninomiya T, Algert C, Arima H, Barzi F, et al. Effects of different regimens to lower blood pressure on major cardiovascular events in older and younger adults: meta-analysis of randomised trials. BMJ 2008;336:1121-3.

16 Law MR, Morris JK, Wald NJ. Use of blood pressure lowering drugs in the prevention of cardiovascular disease: meta-analysis of 147 randomised trials in the context of expectations from prospective epidemiological studies. BMJ 2009;338:b1665.

17 Elliott WJ, Meyer PM. Incident diabetes in clinical trials of antihypertensive drugs: a network meta-analysis. Lancet 2007;369:201-7.

18 Lawes CM, Parag V, Bennett DA, Suh I, Lam TH, Whitlock G, et al. Blood glucose and risk of cardiovascular disease in the Asia Pacific region. Diabetes Care 2004;27:2836-42.

19 Sarwar N, Aspelund T, Eiriksdottir G, Gobin R, Seshasai SR, Forouhi NG, et al. Markers of dysglycaemia and risk of coronary heart disease in people without diabetes: Reykjavik prospective study and systematic review. PLoS Med 2010;7:e1000278.

20 Lawlor DA, Fraser A, Ebrahim S, Smith GD. Independent associations of fasting insulin, glucose, and glycated haemoglobin with stroke and coronary heart disease in older women. PLoS Med 2007;4:e263.

21 Sarwar N, Gao P, Seshasai SR, Gobin R, Kaptoge S, Di Angelantonio E, et al. Diabetes mellitus, fasting blood glucose concentration, and risk of vascular disease: a collaborative meta-analysis of 102 prospective studies. Lancet 2010;375:2215-22.

22 Barzilay JI, Davis BR, Cutler JA, Pressel SL, Whelton PK, Basile J, et al. Fasting glucose levels and incident diabetes mellitus in older nondiabetic adults randomized to receive 3 different classes of antihypertensive treatment: a report from the Antihypertensive and Lipid-Lowering Treatment to Prevent Heart Attack Trial (ALLHAT). Arch Intern Med 2006;166:2191-201.

23 ADVANCE Collaborative Group, Patel A, MacMahon S, Chalmers J, Neal B, Billot L, et al. Intensive blood glucose control and vascular outcomes in patients with type 2 diabetes. N Engl J Med 2008;358:2560-72.

24 Chobanian AV, Bakris GL, Black HR, Cushman WC, Green LA, Izzo JL Jr, et al. Seventh report of the joint national committee on prevention, detection, evaluation, and treatment of high blood pressure. Hypertension 2003;42:1206-52.

25 Mancia G, De Backer G, Dominiczak A, Cifkova R, Fagard R, Germano G, et al. 2007 guidelines for the management of arterial hypertension: the task force for the management of arterial hypertension of the European Society of Hypertension (ESH) and of the European Society of Cardiology (ESC). J Hypertens 2007;25:1105-87.

26 Scottish Intercollegiate Guidelines Network. Risk estimatation and the prevention of cardiovascular disease. Guideline No 97. SIGN, 2007.

27 New Zealand Guidelines Group. New Zealand cardiovascular guidelines handbook: a summary resource for primary care practitioners. NZGG, 2009.

28 Psaty BM, Lumley T, Furberg CD, Schellenbaum G, Pahor M, Alderman MH, et al. Health outcomes associated with various antihypertensive therapies used as first-line agents: a network meta-analysis. JAMA 2003;289:2534-44.

Accepted: 2 November 2011

Cite this as: BMJ 2011;343:d8078.

(c) BMJ Publishing Group Ltd 2012 


\section{Figure}

- Angiotensin converting enzyme inhibitors

- - - Thiazides and related diuretics

---- Angiotensin II receptor antagonists

-- Calcium channel blockers

- $\beta$ adrenoceptor blocking drugs

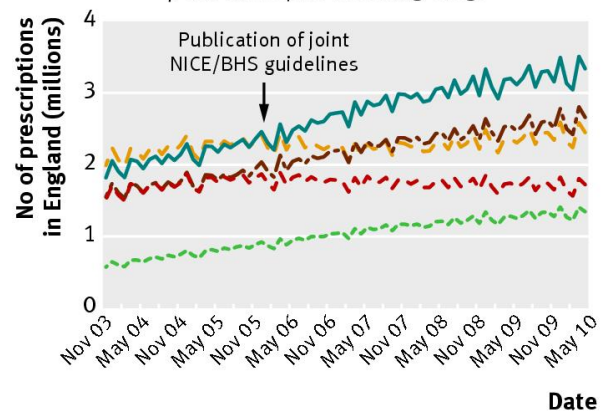

Fig 1 Effect of 2006 NICE/British Hypertension Society guidelines on prescribing rates for all classes of antihypertensive drugs in England (data from NHS Prescriptions Service) 